\title{
Ambiguity and therapy in risk management
}

\author{
Tom Horlick-Jones • Jonathan Rosenhead
}

Received: 6 November 2012/ Accepted: 21 May 2013/Published online: 9 July 2013

(C) Springer-Verlag Berlin Heidelberg and EURO - The Association of European Operational Research Societies 2013

\begin{abstract}
Ambiguity, the existence of multiple plausible (though possibly contested) ways of making sense of the characteristics of decision situations, can present significant difficulties for a wide range of risk management tasks. We will argue that ambiguity is present in risk management situations to a far greater extent that is commonly appreciated. The concept of ambiguity has arisen in different forms across disciplinary literatures and domains of practice. In this paper, we situate our experience of finding ways of supporting planning and decision-making processes concerned with ambiguous risks in the context of those wider perspectives. Our own efforts have employed a hybrid form of problem structuring methods (drawn from operational research and management science) and ethnography (drawn from sociology and anthropology). These engagements with organisational and inter-organisational risk management issues have led us to recognise that 'untangling' otherwise intractable risk management problems may be regarded, in some sense, as a therapeutic process. In this paper, we develop this therapeutic interpretation of the untangling of collective ambiguities using illustrations from a concrete problem situation. We set this therapeutic reading of decision processes in the context of wider perspectives, including those drawn from Habermas' theorisation of communication, the sociology of science and the literature on citizen engagement and deliberation processes.
\end{abstract}

Keywords Organisational risk management - Ambiguity $\cdot$ Uncertainty $\cdot$ Plural rationalities · Ethnomethodology · Problem structuring methods · Practical reasoning - The metaphor of psychotherapy · Engagement - Transdisciplinarity

\footnotetext{
T. Horlick-Jones $(\bowtie)$

School of Social Sciences, Cardiff University, Cardiff, Wales, UK

e-mail: Horlick-JonesT@cardiff.ac.uk
}

\section{J. Rosenhead}

Management School, London School of Economics and Political Science, London, UK 


\begin{abstract}
Jill can see Jack can't see
and can't see he can't see.

Jill can see WHY

Jack can't see,

but Jill cannot see WHY

Jack can't see he can't see.

R.D. Laing, Knots
\end{abstract}

\title{
Introduction and background
}

With this paper, we will review some cross-disciplinary aspects of the interrelationship between decision-making and risk management processes. We do so by focusing on the concepts of ambiguity and therapy. Ambiguity characterises certain kinds of decision problem which feature the existence of multiple plausible (though possibly contested) ways of making sense of the 'facts of the matter'. We will argue that an important, and perhaps surprisingly large, class of risk management tasks share these characteristics, so having the tendency to render them difficult, confusing or possibly intractable. We go on to argue that such problematic situations may be 'untangled' in ways reminiscent of the 'working through' of problems in psychotherapeutic processes.

Our approach draws on our collaborative work, carried out over some two decades, in which we have brought together ideas and methods from our main disciplinary homes of sociology and operational research (Rosenhead and HorlickJones 1995; Horlick-Jones et al. 1998, 2001; Horlick-Jones and Rosenhead 2002; 2007; Horlick-Jones and Sime 2004; Rosenhead 2005). Our initial interest in ambiguity arose from our recognition of the apparent congruence in form between two kinds of problematic decision-making situations, both of which were ill-suited for orthodox decision support (Rosenhead and Horlick-Jones 1995). We came to appreciate that both kinds of situation displayed ambiguity.

The first of these kinds of situation, which had been addressed in the risk management literature, had led eventually to a realisation of the need for the development of new tools to provide appropriate decision support (Funtowicz and Ravetz 1985, 1992). The second kind, associated with the decision-making and management literatures, had already generated an extensive programme of empirical work on 'soft' methods (Eden and Radford 1990; Rosenhead and Mingers 2001). The interesting question, it seemed to us, was whether these soft methods which had been developed to provide decision support in the latter context could be helpfully applied in the former context; namely in supporting the management of ambiguous risks.

The risk management literature mentioned above highlighted situations featuring multiple actors possessing plural rationalities, together with combinations of systems uncertainty, high stakes, and urgency. Importantly, these situations invert the classical combination found in decision theory of 'hard' science and 'soft' values; instead we have 'hard' value-laden decisions and 'soft' scientific inputs (Funtowicz and Ravetz 1985, 1992). On the basis of this diagnosis, Funtowicz and 
Ravetz $(1985,1992)$ advocated the development of a new set of risk management practices-'post-normal science'—which would involve multiple stakeholders in decision processes in dynamic and interactive ways.

The main argument here was that such messy risk management situations necessitate the development of means to accomplish an integration and contextualisation of multiple forms of knowledge. Engaging with a wider range of both expert and informal sources of knowledge would allow contested values and sources of uncertainty, as well as the possible impacts of related matters, to be incorporated into the decision-making process (Horlick-Jones et al. 2001). At that time, it was not entirely clear what sort of processes and techniques would be needed to accomplish these tasks, although there are clear similarities between Funtowicz and Ravetz's vision and the form of some subsequent experiments in citizen engagement (Renn et al. 1995; Horlick-Jones et al. 2007; National Research Council 1996, 2008).

The operational research literature had become progressively engaged with certain kinds of problematic decision situations. These were variously described as 'practical' or 'wicked' problems', 'messes', or 'from the swamp' (e.g. Ravetz 1971; Rittel and Webber 1973; Ackoff 1979; Schön 1983). Such problems are typically ill-defined, have many stakeholders with distinctive perspectives or conflicting interests, and incorporate intangibles and uncertainties. In response to the crisis they created for the traditional operational research paradigm, a class of problem-focused methods with diverse intellectual and practical lineages emerged during the 1980s as a unified candidate for that alternative paradigm; these were known as problem structuring methods (PSMs).

Problem structuring methods are model-based approaches designed to assist management groups to agree the nature and boundaries of the problems that they must tackle, and to secure shared commitments to action. In technical terms, they relax a number of assumptions that decision analysts have traditionally made about decisionmaking. This results in uncertainties being captured as alternative possibilities rather than as numerical probabilities. Value differences are embraced and accommodated, rather than traded-off by means of an additive value function. Complexity is captured and represented not by algebra but diagrammatically. Whilst this limits the mathematical operations that can be performed, it has a range of practical advantages. Factors which escape quantification need not be excluded; the resulting more transparent formulations permit fuller involvement of decision makers; and the resulting enhanced 'ownership' of the process tends to generate greater commitment to its outputs. Claims are also made that the interactive and participatory nature of model development encourages trust and understanding between participants (Checkland 1981; HorlickJones et al. 2001; Rosenhead and Mingers 2001; Friend and Hickling 2005).

This paper draws upon the programme of work in which we set out to operationalise post-normal science using PSMs. ${ }^{1}$ In practice, the main focus of our efforts became organisational and inter-organisational risk management processes, rather than the wider societal risk conflicts which were central to Funtowicz and Ravetz's $(1985,1992)$ interests. Our engagement with organisations was made possible by our provision of consultancy-style support in which we attempted to assist them with the resolution of

\footnotetext{
${ }^{1}$ See also the related efforts collected in the volume edited by Grauer et al. (1985), and the work of Schön and Rein (1994).
} 
problematic planning and decision-making situations that they faced. In this way, we were able to gain access to naturally occurring problem situations. We utilised ethnographic methods to gain rich insights into the nature of these organisations, their patterns of work, and their problems, which in turn supported the design and implementation of our PSM-based interventions involving groups of key players. ${ }^{2}$

We appreciate that in developing our therapeutic reading of risk-related decision processes, we have covered a great deal of territory in terms of disciplinary literatures. Our main orientation is towards work contained in the decision-making, operational research, sociology of risk, and various therapeutic literatures. However, we also consider wider perspectives that draw upon social theory, in particular the work of Jürgen Habermas, and the bodies of work that have developed around citizen engagement and deliberation practice, and the sociology of science. In structuring the manuscript, we have attempted to strike a balance between sufficient signposting and clarity about the interrelationship of ideas, and the avoidance of a cumbersome and over-pedantic text.

Our main objective has been to explore the plausibility of understanding realworld risk management-related decision processes in terms of the notions of ambiguity and therapy. We suggest that ambiguity, in some shape or form, afflicts such processes to far greater extent that is commonly appreciated. We also argue that the need for processes that are, in some sense, therapeutic are necessary to resolve satisfactorily the tangled nature of such ambiguous risk situations.

It should be stressed that here we are deploying a therapeutic metaphor at the level of collective interaction, rather than suggesting that the obstructions we sought to dissolve were located 'in the minds' of individual stakeholders. This is an important distinction. We are emphatically not advancing a psychological mechanism for the resolution of decision problems. Rather, our analytic focus remains resolutely at the level of collective interaction. As we will come to argue, the individual participants in the PSM workshops we ran might be regarded as vehicles for socially shared ways of reasoning, acting and accounting for actions, and the interventions may be seen as occasions for working through collectively held tangles that obstruct consensual progress.

\section{Conceptualising ambiguous risks}

“...as we know, there are known knowns; there are things we know we know. We also know there are known unknowns; that is to say we know there are some things we do not know. But there are also unknown unknowns- the ones we don't know we don't know."

\section{Donald H. Rumsfeld, February 2002}

\footnotetext{
2 The manner of our ethnographic engagement with these social worlds of practice was shaped, to a significant degree, by a style of investigation known as ethnomethodology (Garfinkel 1967; Button 1991; Lynch 1996). As such, it was focused on making visible the processes of practical reasoning and action by which the activities we were observing were practically accomplished. This style of sociological practice is concerned with replacing a traditional emphasis on theorisation, with a focus on explicating observable patterns of naturally occurring situations. Although we both operate within our disciplinary communities, there is a sense in which we have found common cause in a shared primary interest in praxis rather than theory. In that sense, our work could be regarded as exploring the contours of a transdisciplinary engagement with real-world activities (Horlick-Jones and Sime 2004).
} 
Despite being greeted by parts of the media as confirming Donald Rumsfeld's capacity for gobbledegook, his presentation of the perils of uncertainty in decision situations was, of course, basically sound. A situation of known unknowns is classically recognised as a situation of decision-making under risk. Here, there exists a set of possible outcomes of a given decision situation, to which probabilities can be assigned. The occurrence of unknown unknowns, however, creates a situation of decision-making under uncertainty, and an enormous literature now exists which seeks to develop analytic machinery to support such decision-making. Going one step further in terms of the difficulty presented are situations concerning unknown unknowns where the information available to inform a decision is inconsistent or, to make matters even worse, contested. Such situations have been described as ambiguous or possessing 'uncertain uncertainty' (Kleindorfer et al. 1993; March 1988; Alvesson 2004).

How are these decision-analytic notions related to the real world of risk management? Decision-making under risk, as defined above, assumes that preferences and values can be stated without equivocation, and do not change. In contrast, risk in real world settings is about managing multiple, sometimes dynamic, contingencies in pragmatic and cost-effective ways, where the resulting outcomes may be differently valued by multiple stakeholders; the action-consequence link may be problematic; and where important factors and issues may be unquantifiable. Moreover, such processes may take place in settings characterised by complexity, urgency, and high stakes, about which the decision makers may have far from perfect knowledge (see e.g. Benton 1990; Klein et al. 1993; Mandel 1996; Renn 2008; Tett 2009).

Two or three decades ago, the organisational theorist James March (1988) noted the gap between decision theoretic conceptions of risk and the practical understandings of risk commonly held by managers. His research suggested that managers were more pre-occupied with specific performance targets than in probability estimates, and with the avoidance of undesirable outcomes. More recent work, on decision-making in real-world risk-related situations like those that occur within aerospace, military, and surgical settings, has served to underline the rather limited relevance of classical decision theory for actors facing real-time choices concerning complex and ambiguous risks. Here, it has been recognised that such decision-making processes are typically both dynamic and embedded within a range of wider considerations. In such challenging circumstances, effective decision-making becomes primarily a matter of experience-based practical reasoning involving pattern recognition, rather than pure calculation (e.g. Klein et al. 1993).

The role of ambiguity in, for example, escalating the cost of insurance against certain risk issues, or in making some contingencies uninsurable, has been recognised for some years (Kunreuther 1989; Kunreuther et al. 1995). More recently, efforts within industry and elsewhere to find ways of managing ambiguous risks in appropriate ways have focused on the need to broaden the knowledge base and range of stakeholders involved in associated decision processes (UKOOA 1999; AIRMIC 2000; Klinke and Renn 2002; Sharpe 2004; IRGC 2005; RSSB 2006). 
These recent developments concerning the management of ambiguity have coincided with a period where a formal discourse of risk has come to play a central role in codifying and regulating organisational and professional practices (NAO 2000, 2004; Power 2004). The satisfactory management of a portfolio of 'key risks' is now regarded by business and government alike as providing the basis for sound corporate governance. Within this regime, a range of traditional organisational concerns, not all of which might have previously been regarded as especially 'risky', for example the failure to manage a project adequately, or the loss of a good reputation, have been re-cast in terms of risk categories. In this way, risk issues might now be regarded as being constituted by the very discourse that purports to offer a means to manage them. In this sense, risk is

'not a first order thing ... but is the product of specific social, organizational and managerial processes by which various objects get recognised and described as risks' (Power et al. 2009: 303)

Although this view now has an influential role within the sociological, management, and organisational studies literatures, serious questions can be raised about its capacity to capture the totality of risk-related behaviours in organisational settings. In practice, the new 'risk management society' has brought into existence a rather more complicated organisational dynamics. As we will discuss below, there is now an overlap between formally constituted risk issues and a range of other issues that are, in some sense, 'risky'. That this should occur is not wholly surprising, given what has been known for many years about the role of informal behaviours within organisations (e.g. Dalton 1959; Roy 1960; Goffman 1972; Jackall 1988).

Our empirical experience of working with organisations has served to highlight two ways in which informal behaviours complicate the picture. First, there exists a slippage between formal risk management procedures and the informal practices by which those official commitments are practically accomplished. Second, there often exist multiple informal pre-occupations associated with the ostensible risk issue, which serve to create an ambiguity about the nature of the risk issue itself. In such real-world settings, everyday risk-related practices are shaped by the informal logics that emerge through actors' practical engagement with the tasks at hand. In practice, issues of overload and resource constraint, experience, wider agendas and concerns, and the micro-politics of blame and social accountability all play their roles (Prior, 2001; Horlick-Jones 2005a, b; Corvellec 2009; Broadhurst et al. 2010; Molotch and McClain 2008).

One of us has described this perspective on the dynamics of risk in organisational life as constituting a decentred model of the nature of risk (Horlick-Jones 2005a, b, 2008; see also related work by Molotch 2012). According to this view, risk is present not only in the form of contingencies for which there is a formal shared appreciation of significance, but also for those for which sectional, unofficial or personal interests exist among the interacting agents. The presence of risk in its various forms creates a challenge to the actors' capacity to account—both formally and informally—for their behaviours in satisfactory ways, so creating the possibility of a micro-politics of blame. Seen from this perspective, there is a tendency for a kind of ambiguity to arise simply from the ongoing practical accomplishment of risk management in organisational life. There is ambiguity in the very nature of the 'risk object' to which actors are orienting at any given moment. 
So it seems that ambiguity in its various forms may be more common in organisational life than might be expected. Renn (2008) and Klinke and Renn (2002) draw a distinction between interpretative ambiguity (evidence is disputed) and normative ambiguity (values are disputed). March (1988) goes further, identifying four possible kinds of ambiguity in organisational decision-making: about preferences, about links between actions and accounts of actions, about connections between past and present, and of interpretation. His 'garbage-can' model of organisational decision-making sees ambiguity as having the capacity to render organisations as 'organised anarchies', in which the convoluted behaviours of actors can only be understood in terms of their local logics. Our work with organisations in seeking to support their management of risk suggests that March's model is helpful in capturing the associated organisational dynamics. ${ }^{3}$

The literary critic William Empson (1961) famously asserted that there are 'seven kinds of ambiguity'. His analysis identifies multiple nuances of purposeful or accidental meaning that the presence of ambiguity in a text can achieve. Our discussion of the role of ambiguity in organisational risk management suggests that appropriate means of decision support need to have the capacity to be sensitive to a similar range of formal and informal meanings and commitments.

\section{Tangles in organisational risk management}

Let us consider an empirical illustration of the sort of ambiguity-afflicted risk management situation that we have in mind. The sequence of data at Fig. 1 is drawn from a study we conducted, which was associated with the strategic planning of an annual carnival. This study was supported by the UK Economic and Social Research Council, as part of a major programme of research into risk issues. The carnival in question was, in effect, a loosely controlled street celebration involving large number of revellers (up to one million in number), loud music, dancing, various artistic performances, a procession involving vehicles, and the local production, sale and consumption of ethnic foods.

The data ${ }^{4}$ are drawn from a recording of a planning meeting which brought together representatives of a diverse group of stakeholder organisations with an

\footnotetext{
3 There is a close similarly between Boden's (1994) notion of 'local logics', which she uses to draw out the resonance between the garbage-can model and her ethnomethodological view of organisational life, and our own use of the notion of 'informal logics' which shape risk-related behaviours.

${ }^{4}$ Here, we have used a simplified form of the transcription notation developed by conversation analysts (see e.g. Peräkylä et al 2008) in order to capture the intricate dynamics of this exchange:

[ The point where current speaker's talk is overlapped by another's talk

$=$ No gap between lines

(.4) Elapsed time in tenths of a second

(.) A tiny gap, probably no more than one-tenth of a second

() Presence of an unclear fragment on the tape

(()) Researcher comments within double parentheses

: Prolongation of immediately prior sound

score Some form of stress, via pitch and/or amplitude

** Utterance at low volume in contrast to surrounding talk.
} 
1 M1 now in terms of the opportunity (.)I'll try to wind up quickly(.)because( )

2 (.4)I think(.)I want to talk about this question of down(.)down=

3 sizing(.)the audience(.)I think it's an opportunity (.)if you ( $)()=$.

$4 \quad((\mathrm{M} 2))($.$) it's no good smiling (.)^{*}$ commo::: ${ }^{*}$ you $()=$.

$5 \quad$ [you know

6 M2 [it's a question that you asked and you're answering and nobody else

$7 \quad$ will ask a question about downsizing

$8 \quad$ M1 well I ( )that's why I'm raising it

9 M2 it's not a question(.)it's just another attitude statement of yours

$10 \quad(.2)$

11 Mod I think(.)think we'd still like to capture all this(.)so

12 ? okay

13 M1 I think(.)fundamental(.)in which case then(.)I would like to say that I

14

15

16

17 think it's fundamental to the future of the Carnival(.)is dealing with the question of what kind of event is it and what is your audience(.)and I think an indefinite growth strategy is the road to ruin(.)I think that will destroy the event(.)but that's( )

Fig. 1 Talk from a planning meeting. Reproduced with permission from (Taylor\& Francis Ltd). (Horlick-Jones et al 2001; Horlick-Jones 2005a)

interest in the future of the carnival. M1 is a local government officer who is making a presentation. M2 is closely associated with groups involved in organising the carnival, and he is sitting physically close to M1. Mod is the workshop facilitator.

At the time of our involvement, the scale of the carnival had grown to the extent that its size was creating difficulties for a range of practical tasks concerned with maintaining the safety of the revellers. In the discussion something of an impasse had occurred about how best to deal with these difficulties. The sequence begins with M1 setting out the advantages, as he sees it, of reducing the size of the carnival crowd. At this point M2 engaged in non-verbal gestures which suggested he was very unhappy about M1's observations. At the end of line 3, M1 pauses, and then, at the start of line 4, he utters M2's name and a somewhat confrontational exchange between them follows. Were M1 and M2 talking at cross purposes?

In seeking to make sense of what was going on in this exchange, we were able to draw upon extensive ethnographic investigations of what one might call the backstage' of this performance. In this way, we were able to generate an empathic reading of what the actors had to say (or preferred not to say). Our understanding is that M2 took the view that constraining the size of the crowd threatened the historically fashioned function of the carnival as symbolically representing the freedom, particularly among ethnic groups, to 'reclaim the streets'. According to this perspective, M1's 'downsizing' proposal was simply unacceptable. Importantly, M1's argument seems to have been heard by some participants in the meeting as a 'political' statement reflecting an underlying hostility to the carnival. Some even regarded his views as a cynical attempt to mask such sentiments in terms of ostensibly 'technical' issues.

The planning impasse that we encountered reflected such conflicts and misunderstandings. This was compounded by the carnival having a history of various sorts of conflict, resulting in the stakeholder groups not really trusting each 
other. Decisions could not be made in such a way as to command consensual support from all the key stakeholders. In terms of Renn's (2008) perspective, both interpretative and normative ambiguities were present, suggesting the need to involve stakeholders in an interactive decision process.

This particular situation was complicated by a diversity of stakeholder understandings of the ostensible risk issue; namely the safety of the carnival. Some, for example, regarded the precarious finances of the carnival as their chief focus. We had also found clear evidence that some stakeholder groups were strongly motivated by what they regarded as threats to issues like the symbolic significance of the carnival. However, these latter concerns were largely unarticulated in the context of multi-stakeholder planning meetings.

The complexity of this short sequence of data is striking, as indeed is the extent to which overlapping nuances of meaning are woven together by the actors in a situated moment-by-moment manner. This is a very different sort of situation from a classically defined decision context in which preferences can be unequivocally specified.

In this and other projects there seemed to be a clear resemblance between the patterns of systematic misunderstanding in evidence and the pathologies of interpersonal perception and interaction captured in the therapy-related programme of Ronald Laing and his associates $(1966 ; 1970)$. Inspired by Laing's notion of a 'knot' (see the short extract at the very start of this paper), we began to think in terms of 'tangles': collectively produced confusions of discourse and practical reasoning that served to obstruct progress with the resolution of associated planning and decision-making processes. We went on to consider whether there might be a useful analogy between such tangled formations and the notion of a neurosis (or 'blockage') in psychotherapy (Horlick-Jones et al. 1998, 2001).

In practice, we were able to provide effective decision support for difficult planning situations of this nature, using our hybrid combination of ethnography and customised combinations of parts of PSMs. In so doing, it seemed that we were able to help stakeholders 'work through' collectively held tangles, so as to achieve practical and consensually acceptable ways of making progress. Our programme of work has included major interventions concerned with the safety of a public corporation's fleet of vehicles and the production of a safety standard for use on a national rail network. For the purposes of this paper, however, we will concentrate on our initial work with the carnival which we have just described. That work was instrumental in encouraging the establishment of a large-scale safety review, which recognised our work in the following terms (GLA 2004):

'...I would also like to acknowledge the decision-making support provided by [the authors]. In 1997 and 1998 [they] carried out the first detailed analysis of the organisational and inter-organisational risk management processes associated with the [named] carnival. The importance of their work, particularly in the context of the Carnival Review Group's interim recommendations provided the basis upon which the Carnival Public Safety Project was founded'. 
In the remainder of this paper we will explore the extent to which such practical decision support did indeed have a certain resemblance to therapeutic processes. The task of drawing out connections between what was, in effect, an exercise in consulting practice and the precise form of a therapeutic process is, of course, a nontrivial undertaking. Therefore, it is unsurprising that at this stage we are able to indicate only provisional findings.

\section{The plausibility of the therapeutic metaphor}

\section{Introduction}

We are not alone amongst those interested in decision-making in considering its possible relationship with therapeutic processes, although our interest is rather different in nature from that of other researchers. Such comparisons are necessarily complicated by the wide range of psychotherapeutic methods in existence (Kovel 1978), and also by the contrasting nature of what one might call 'mainstream' decision analytic techniques and the 'soft' group decision support methods with which we are concerned here. The work of Capurso and Tsoukiàs (2003) illustrates this difficulty. They identify decision support's use of formal models of rationality to reduce ambiguity, and psychotherapy's creative use of ambiguity as a resource, as important contrasting features of these two spheres of professional practice. Interestingly, according to this perspective, our work would appear to be far closer to psychotherapy in nature than is mainstream decision support.

Fischhoff's (1980) work also draws interesting comparisons between decision analysis and psychotherapy; however, he is focused primarily on what decision analysis can learn from psychoanalysis as a professional activity. He is concerned principally with the deployment and evaluation of professional services, rather than with specific features of the sorts of processes associated with these two areas of practice.

Schein's $(1987,1988)$ work on consultancy support for organisational development draws extensively on ideas developed by the psychologist Kurt Lewin. Those ideas were closely related to an application of psychoanalysis to organisations, and they found their best-known expression in the form of T-Groups (de Board 1978). Schein's use of such groups, to engender mutual appreciation and understanding within an organisation's personnel, is strongly reminiscent of the PSM-based interventions on which we report in this paper. Importantly, we share Schein's focus on paying particular attention to the informal behaviours by which formal organisational procedures are accomplished in practice. The properties displayed by groups in achieving such mutual appreciation have been highlighted by a number of management authors, perhaps most memorably by Phillips and Phillips (1993). These particular authors in turn draw upon the work of the group psychotherapist Wilfred Bion (1961), who pioneered understanding of the 'emotional life' of groups, and its capacity to allow group participants to identify mutual 'enemies', and so develop shared commitments to action. 
Also within the management science literature, Holt's (2004) paper is specifically about risk management, and he shares with us a pre-occupation with the difficulties that 'wicked' problems pose for associated decision-making. He, too, is interested in therapeutic processes, but within a more conventionally Freudian framework. Interestingly, based on the purely theoretical considerations, he advocates the development of the very sort of conversation-based, interactive and exploratory means of supporting the management of ambiguous risks that we discuss in this paper. Indeed, he uses the term 'organizational therapy' (Holt 2004: 253), an expression we introduced independently a few years earlier (Horlick-Jones et al. 1998, 2001).

Therapeutic ideas also feature in Habermas' (1970, 1984) theorisation of communication processes in society. He argues that such processes are systematically distorted, so producing irrationality and inequity. As part of an elaborate examination of the nature and role of language, he identifies what he terms 'therapeutic discourse' as an important component of generating 'communicative competence', in which interlocutors may be regarded as simultaneously adopting 'therapist' and 'client' roles. Much of this work is discussed at a level somewhat abstracted from our focus on everyday interaction. Far closer to our concerns lies the Habermas-inspired programme of citizen engagement, associated most closely with the analytic-deliberative work of Renn et al. (1995). This has now become incorporated into a broader programme of work on risk governance, which, significantly, shares our interest in ambiguity (Klinke and Renn 2002; IRGC 2005; Renn 2008; see also discussion in National Research Council 1996, 2008; HorlickJones et al. 2007). We will return to this topic at the end of the paper.

The nature of therapeutic processes

What, precisely, do we mean by therapeutic processes? We have drawn the central therapeutic metaphor from a variety of talk-based interventions that seek to address behavioural pathologies, and which are deployed across a range of individual, marital, family, and group settings. One might define the core, shared feature of these activities as attempts to provide persons or groups with access to informal knowledge that is in some way held by, yet hidden from, them; the lack of which serves to create 'problems in living' (Storr 1979). The generic therapeutic process might be regarded as constituting a 'working through' of obstacles to desired actions.

There are a number of shared features of therapeutic processes that we wish to highlight (discussed in detail in e.g. Storr 1979; Casement 1985; Peräkylä et al. 2008):

(a). The role of a therapist, who enters into an empathic and trust-based engagement with the client(s) presenting the problem(s).

(b). A process of uninhibited exploration, or free-association, in which the client is encouraged to explore their difficulties in the widest context, including in perhaps unexpected and oblique ways. 
(c). A process of interpretation, in which the therapist helps the client to formulate their views, acts as a 'mirror' to the client, observing possible contradictions and inconsistencies in their views; and helps the client make perhaps unexpected connections.

(d). The conclusion of the process, in which symptoms have been addressed, and the therapist disengages with the client by mutual agreement. The literature makes clear that therapeutic processes may take a very short time, or, more likely, an extended period, in order to make satisfactory progress (Storr 1979; Casement 1985). Our interventions took place in ways that were time-limited by both the resources available and the access arrangements negotiated with the organisations in question. In this respect, our work had a resemblance to what has been termed brief therapy (Weakland et al. 1974), with its characteristic focus on working with the client to identify specific goals and to work towards their achievement.

\section{Carnival intervention as a therapeutic process}

We have described this intervention in detail elsewhere (Horlick-Jones et al. 1998, 2001). Here, we present simply an outline of the activity in order to bring out the resemblance to key elements of a therapeutic process, as set out above. The research grant from the UK Economic and Social Research Council which made the carnival work possible provided us with research support for a period of 28 months during 1996-1999. During this time we worked closely with three main organisations, leading to PSM-based interventions in two of these settings. One of these trial interventions was concerned with the carnival, and this involved a number of stakeholder organisations, in addition to our gatekeeper organisation.

Our work began with an ethnographic investigation, lasting around 12 months, in which we followed two cycles of the planning process which leads to the annual staging of the carnival. ${ }^{5}$ This work was focused on observation of a series of planning meetings, supplemented and enriched by informal meetings, conversations and interviews with key players. We have already illustrated how this work served to provide insights into the convoluted nature of the impasse that was creating problems for carnival planning. We found that the ethnography provided us with a well-informed position that supported our negotiations with our clients over the problem focus for our PSM interventions. This perspective transcended the subjective understandings of any one actor and provided access to informal and largely unspoken aspects of the carnival. These insights provided us with an authoritative role, and an enhanced ability to 'think on our feet', when acting as workshop facilitators.

It seems reasonable to argue that the acquisition of this level of intimate appreciation of the underlying tensions and dynamics of the planning context greatly enhanced our ability to play a 'quasi-therapist' role. We could demonstrate

\footnotetext{
5 We feel that an extended period of ethnographic work is not a necessary feature of the hybrid methodology we have developed. We point to very effective examples of organisational ethnography that have elicited the sorts of insights we sought over far shorter timescales (e.g. Harper 1998).
} 
empathy when actors articulated their own positions, and our attempts at what therapists would call 'interpretation' were clearly well-informed and demonstrated insight. One might even argue that, despite underlying tensions between the stakeholders, we were on a number of occasions able to convene group work in which the participants appeared able to explore new possibilities in a relatively safe 'holding environment' [cf. in particular the work of the psychotherapist Donald Winnicott (e.g. 1971); discussed in Davis and Wallbridge (1981); Phillips (1988); see also Schein (1987)].

Our workshop-based intervention used 'the front end' of Soft Systems Methodology (SSM: Checkland 1981) in order to explore the complexity of the carnival system and to elicit possible options for re-design. This was followed by the use of parts of the Strategic Choice Approach (SCA: Friend and Hickling 2005) to address uncertainty and inter-connectivity and to work towards a package of commitments for future actions. The formal focus of the work was the strategic planning of the carnival, but this quickly led to an examination of a number of interrelated areas: the changing nature of the carnival, financial aspects and commercialisation, the size of the crowd of revellers, and the geographical spread of the carnival area.

The first, SSM-based, workshop was initially focused on exploring different ways of viewing the function of the carnival. Key activities were drawn out, examining how they might be done differently, and the extent that existing activities inhibited their achievement. This analysis led to the identification of key decision areas and feasible options (see Fig. 2). There is a clear similarity here with the free association aspect of therapeutic processes. It seemed clear to us that these activities in the first workshop served to 'open up' the tangled formations that were inhibiting progress through consensual planning. The interactive nature of the workshop provided the participants with insights into each others' various perspectives and motivations in ways reminiscent of the use of 'circular questioning' in family therapy (Penn 1982; Burnham 1986). There was also a clear sense of 'unfreezing' of pre-existing barriers of misunderstanding between participants in the manner of Schein (1987) use of T-Groups.

In the second workshop, we attempted to establish consensual order between participants and a shared commitment to a package of actions. At Fig. 3, we illustrate one component process used in moving towards these objectives. The group had decided to examine possible options for the future funding of the carnival. In the figure, an 'as is' option is being compared with the idea of establishing an enclosed arena where tickets could be sold for viewing carnivalrelated artistic performances. The group were invited to evaluate the relative advantages of these two funding options against a set of criteria they had themselves identified during the first workshop. Clearly, in decision-analytic terms, this is a difficult multidimensional problem, entailing six different value dimensions and a group of stakeholder with very different perspectives on the issues in question.

The aspect of SCA which we used invites the group to agree collectively where the relative advantage of each option lies according to each criterion, one at a time. The degree of uncertainty for each of these judgements is indicated by arrows. The group is then asked to negotiate a shared agreement about which option has the 


\section{Decision Areas \& Options}

\begin{tabular}{|c|c|c|}
\hline Decision areas & Options & \\
\hline \multirow[t]{2}{*}{ Artistic vetting? } & As is & \\
\hline & Yes & \\
\hline \multirow[t]{3}{*}{ Shape of Carnival? } & As is & \\
\hline & Larger area & \\
\hline & Arena & \\
\hline \multirow[t]{2}{*}{ Control of procession? } & As is & \\
\hline & More stewards etc. & \\
\hline \multirow[t]{2}{*}{ Sound systems? } & As is & \\
\hline & Quieter & \\
\hline \multirow[t]{5}{*}{ Funding? } & As is & National subsidy \\
\hline & Charge for arena & Revellers' spending \\
\hline & Event more & Voluntary collection \\
\hline & sponsors & Street trade \\
\hline & $\begin{array}{l}\text { Seed money for } \\
\text { partnership } \\
\text { exploration }\end{array}$ & I1cense Iee +/- \\
\hline $\begin{array}{l}\text { (Co-ordinate) Communication } \\
\text { Strategy? }\end{array}$ & $\begin{array}{l}\text { Promote Carnival's } \\
\text { safety }\end{array}$ & $\begin{array}{l}\text { NCT to develop } \\
\text { communication } \\
\text { strategy }\end{array}$ \\
\hline
\end{tabular}

Fig. 2 'Free association' on the function of the carnival. Reproduced with permission from (Taylor\& Francis Ltd). (Horlick-Jones et al 2001; Horlick-Jones 2005a) 


\section{Comparative Advantage}
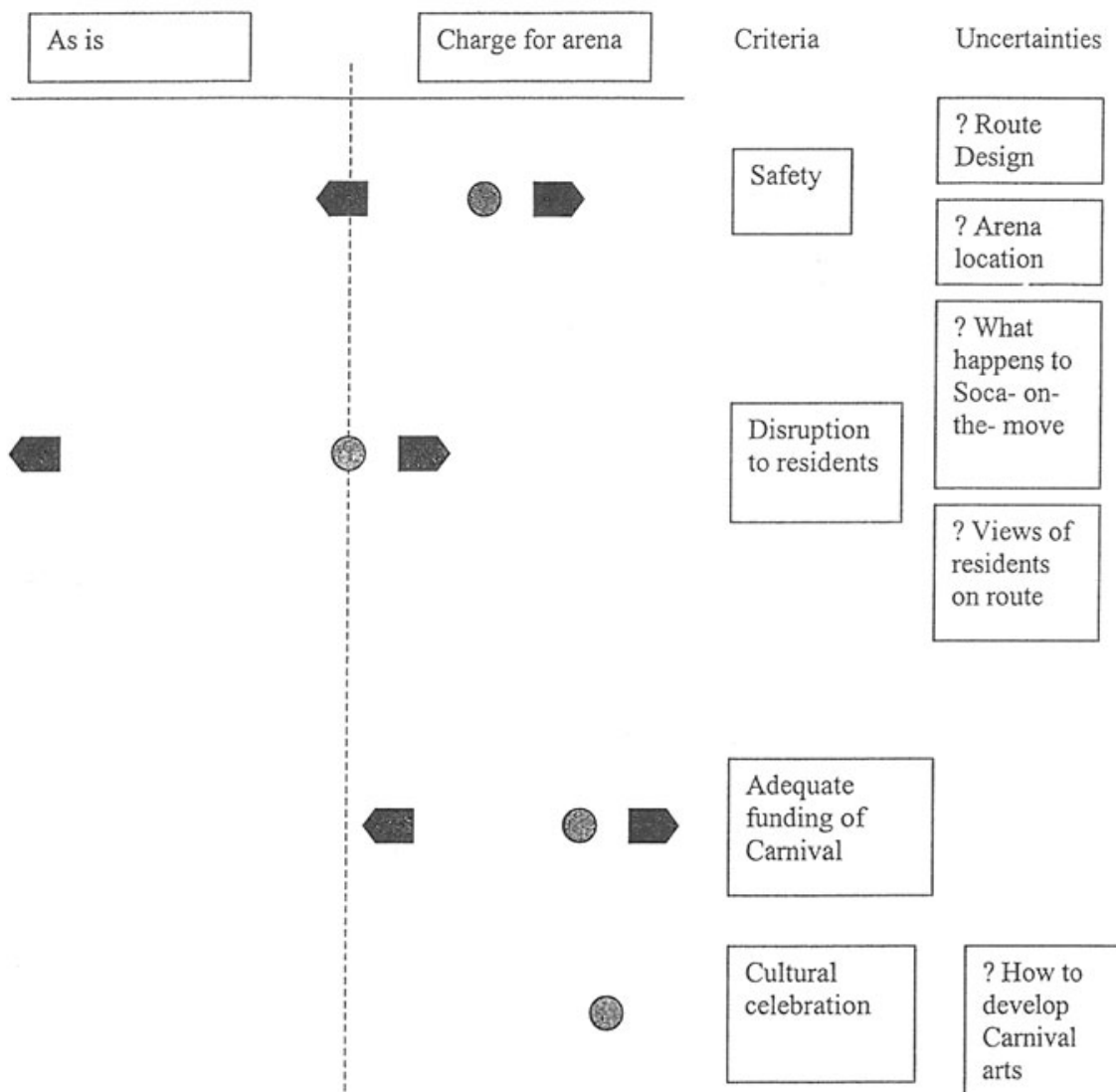

? How to

develop

Carnival

arts

\begin{tabular}{|l|l|}
\hline Public order & $\begin{array}{l}\text { ? Implications } \\
\text { of exclusion }\end{array}$ \\
\hline
\end{tabular}

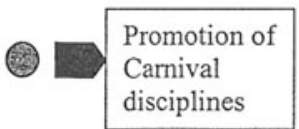

Fig. 3 Working towards establishing consensual order and a shared commitment to actions. Reproduced with permission from (Taylor\& Francis Ltd). (Horlick-Jones et al 2001; Horlick-Jones 2005a) 
overall advantage. In the second workshop, the group agreed that the arena option has significant advantage. Significantly, this result was surprising for all the participants. The process had made possible an inter-subjective (see e.g. Eden et al. 1981; Peräkylä et al. 2008) process that drew upon all the participants' knowledge and experience, and which allowed them to negotiate their way to a shared view, despite their sometimes very different perspectives on the meaning of the carnival. In Schein (1987) terms, a 're-freezing' had been accomplished, in which new ways of working had been made possible following a process of enhancing mutual understanding and exploring options within an 'unfrozen' or fluid state of being. The resemblance to family therapy, especially in its 'brief' mode, is also evident.

\section{Discussion and conclusions}

We have considered the significance of ambiguity in creating challenges for decision support associated with organisational risk management. In so doing, we have suggested that some forms of ambiguity may be rather common in risk management situations. In coming to this conclusion, we have drawn upon what one of us has described as a decentred model of risk, which suggests that ambiguity may exist in the very nature of the 'risk object' to which actors are orienting at any given moment.

We have also reviewed our programme of work in which we have successfully used a hybrid combination of ethnography and PSM techniques in providing decision support to organisations facing complex and ambiguous real-world risk management tasks. We have explored our experience and come to a realisation that these interventions bore some family resemblance to psychotherapeutic processes and have gone on to examine evidence for the plausibility of this metaphor.

The style of our work has been strongly shaped by an ethnomethodological ${ }^{6}$ focus on seeking to make visible the socially shared processes of practical reason and action by which features of the social and organisational settings we have investigated were practically accomplished. This perspective has influenced our adoption of a therapeutic metaphor at the level of collective interaction, rather than suggesting that the obstructions we sought to dissolve were located in the minds of individual stakeholders. According to this perspective, the individual participants in the PSM workshops we ran might be regarded as vehicles for socially shared ways of reasoning, acting and accounting for actions, and the interventions may be seen as occasions for working through collectively held tangles that obstruct consensual progress.

Our more recent thinking in this area has begun to draw out in more explicit terms the influence on our work of the philosopher Ludwig Wittgenstein. Of central significance here is Wittgenstein's (1958) conception of the socially embedded nature of language in terms of language-games, reflecting the intimate interweaving of language use and practical conduct. There are deep connections between Wittgenstein's work and ethnomethodology, and indeed ethnomethodology may be regarded as an empirical programme dedicated to investigating the diverse

\footnotetext{
${ }^{6}$ See note 2 above.
} 
language games through which social order is performed on the street' (Lynch 1996). Wittgenstein regarded philosophical problems as arising from certain kinds of misunderstanding. In his later work, he used the term 'therapy' to describe his 'grammatical' analytical method-which comprised the systematic exploration of meanings, impossible meanings, and connections - as one of seeking clarity, and so 'dissolving' philosophical problems (Baker 2004).

There seems to us to be a clear resonance between this Wittgensteinian notion of therapy, and the sort of processes that we were able to engender using the hybrid methodology described in this paper. We feel that this recognition has important conceptual implications for understanding both the nature of our programme of work and the focus of our interventions.

Finally, we return to the possible similarities between our work and Renn's Habermas-inspired programme of work on citizen engagement and deliberative dialogue, with its interest in 'therapeutic' discourse (see especially Webler 1995) and ambiguity. We should also note the wider literature on citizen engagement (National Research Council 1996, 2008; Horlick-Jones et al. 2007). In drawing upon ideas from the sociology of scientific knowledge, the engagement literature ostensibly addresses issues present in our own work, in particular concerning the relationship between uncertainty and what might be called 'value conflicts' (e.g. Wynne 1992; Tait 2001). To what extent, one might ask, are we presenting a distinct perspective?

In responding to this challenge, we return to Fig. 1, and our observation about the complexity of this sequence of data and the extent to which overlapping nuances of meaning are woven together by the actors in a situated moment-by-moment manner. We have already made the point that this is a very different sort of situation from a classically defined decision context in which preferences can be unequivocally specified. We would go further, and point to what we regard as a degree of reification in both Habermas' perspective, and in that of the mainstream sociology of science. By this we mean the tendency of both theorisations to be relatively insensitive to the situated dynamics of social interaction.

The Habermas-inspired programme of citizen engagement has a formal commitment to certain kinds of 'therapeutic' interaction. However, this is incorporated within a framework in which a universal notion of rationality plays a central role. As such, it is very different in nature from our own perspective, which is far closer to the notion of 'order without rules' (Bogen 1989, 1993; Lynch 1993). In a similar way, we regard the mainstream sociology of science's interest in values as being inadequately static in comparison with the melting-pot dynamism of what Lynch (1992b: 299) has termed the 'discursive collage' of real-world social interaction. $^{7}$ Ultimately, of course, these differences of interpretation and

\footnotetext{
7 Here, we draw upon a tightly argued debate within the sociology of science which took place over 20 years ago between Michael Lynch (1992a, b) and David Bloor (1992). Lynch took an ethnomethodological view of things, and Bloor a position close to the mainstream of the sociology of scientific knowledge. Interesting, both were inspired by readings of Wittgenstein's work on the nature of rules. In essence, Bloor saw classically theorised social variables, or values, as serving to shape the form of scientific knowledge. Lynch regarded the situated dynamics of social interaction as being more radically constitutive of the emergence of order and knowledge than Bloor's 'social shaping' thesis. A state of impasse between these positions continues to exist in the literature. Horlick-Jones (2005a) has explored the diversity of such situated dynamics of social interaction in the context of risk-handling processes.
} 
perspective are matters that require empirical investigation. There is a clear need for detailed examination of the social praxis associated with our own interventions, and those carried out by researchers working along broadly similar lines, but with distinct conceptual orientations.

We have argued in this paper that our own empirical work can be seen as providing strong support for a more radically situational appreciation of the nature of decision processes. We also regard our (collective interaction) version of a therapeutic approach to decision support as having considerable practical and conceptual promise. We suggest that investigations involving interventions of this kind offer much in terms of deepening both scholars' and practitioners' understanding of the nature of decision processes.

Acknowledgments The empirical illustrations in this paper draw upon work supported by the Economic and Social Research Council (awards L211252044 and L211272006) and the BP/CARR Complex Risk programme. We are pleased to acknowledge the cooperation of those organisations associated with the Notting Hill Carnival with which we worked in 1997-1998, and again in 2001. During recent years our membership of the European PACHELBEL consortium (2010-2012) has served to extend and refine our understanding of some of the themes we have addressed in this paper. We wish to thank our PACHELBEL colleagues, and in particular Ana Prades, for invaluable conversations and friendly collaboration. Mick Bloor, Clare Kell, Lorenzo Marvulli, Ana Prades and Andrew Sharpe also provided helpful comments on earlier versions of this paper, for which we are most grateful. Finally, we wish to thank the referees and guest editors for their efforts. We are most grateful to Taylor and Francis Ltd. for permission to reproduce Figures 1, 2 and 3 in this paper. The original publications may be found in Horlick-Jones et al 2001 'Decision support for organisational risk management by problem structuring', Health, Risk \& Society, Vol 3, no 2, pp.148-165, and Horlicks-Jones 2005a 'Informal logics of risk: contingency and modes of practical reasoning', Journal of Risk Research, Vol 8, no 3, pp.253-272.

\section{References}

Ackoff R (1979) The future of operational research is past. J oper Res Soc 30: 93-104

AIRMIC (2000) 'Ambiguous risks: an obstacle to effective corporate decision-making', press release from the Association of Insurance and Risk Managers, London, 10th May

Alvesson M (2004) Knowledge work and knowledge-intensive firms. Oxford University Press, Oxford

Baker G (2004) Wittgenstein's method: neglected aspects. In: Morris K (ed). Oxford University Press, Oxford

Benton P (1990) Riding the whirlwind: Benton on managing turbulence. Blackwell, Oxford

Bion W (1961) Experiences in groups and other papers. Tavistock, London

Bloor D (1992) Left and right Wittgensteinians. In: Pickering A (ed) Science as practice and culture. University of Chicago Press, Chicago, pp 266-282

Boden D (1994) The business of talk: organizations in action. Polity, Cambridge

Bogen D (1989) A reappraisal of Habermas theory of communication action in the light of detailed investigation of social praxis. J Theory Soc Behav 19(1):47-77

Bogen D (1993) Order without rules: Wittgenstein and the "communicative ethics controversy". Sociol Theory 11(1):55-71

Broadhurst K, Hall C, Wastell D, White S, Pithouse A (2010) Risk, instrumentalism and the humane project in social work: identifying the Informal logics of risk management in childrens' statutory services. Br J Soc Work 40:1046-1064

Burnham J (1986) Family therapy: first steps towards a systemic approach. Tavistock, London

Button G (ed) (1991) Ethnomethodology and the human sciences. Cambridge University Press, Cambridge

Capurso E, Tsoukiàs A (2003) Decision aiding and psychotherapy. Newsletter of the European working group on multi-criteria aid for decisions 3(8):1-4 
Casement P (1985) On Learning from the Patient. Tavistock Publications, London

Checkland P (1981) Systems thinking, systems practice. Wiley, Chichester

Corvellec H (2009) The practice of risk management: silence is not absence. Risk Manag 11(3-4):285-304

Dalton M (1959) Men who manage: fusions of feeling and theory in administration. Wiley, New York

Davis M, Wallbridge D (1981) Boundary and space: an introduction to the work of D. W. Winnicott. Penguin, Harmondsworth

de Board R (1978) The psychoanalysis of organizations: a psychoanalytic approach to behaviour in groups and organizations. Tavistock, London

Eden C, Jones S, Sims D, Smithin T (1981) The intersubjectivity of issues and issues of intersubjectivty. J Manag Stud 18(1):37-47

Eden C, Radford J (eds) (1990) Tackling strategic problems: the role of group decision support. Sage, London

Empson W (1961) Seven types of ambiguity. Penguin, Harmondsworth

Fischhoff B (1980) Clinical decision analysis. Oper Res 28:28-43

Friend J, Hickling A (2005) Planning under pressure: the strategic choice approach, 3rd edn. Elsevier Butterworth-Heinemann, Oxford

Funtowicz S, Ravetz J (1985) Three types of risk assessment: a methodological analysis. In: Whipple C, Covello V (eds) Risk analysis and the private sector. Plenum, New York, pp 217-231

Funtowicz S, Ravetz J (1992) Risk management as a post-normal science. Risk Anal 12(1):95-97

Garfinkel H (1967) Studies in Ethnomethodology. Prentice-Hall, Englewood Cliffs

GLA (2004) Notting Hill carnival: a strategic review. Greater London Authority, London

Goffman E (1972) Interaction ritual. Penguin, Harmondsworth

Grauer M, Thompson M, Wierzbicki A (eds) (1985) Plural rationality and interactive decision process, lecture notes in economics and mathematical systems 248. Springer-Verlag, Berlin

Habermas J (1970) On systematically distorted communication. Inquiry 13:205-218

Habermas J (1984) The theory of communicative action, vol 1. Beacon Press, Boston

Harper R (1998) Inside the IMF: an ethnography of documents, technology and organizational action. Academic Press, San Diego

Holt R (2004) Risk management: the talking cure. Organization 11(2):251-270

Horlick-Jones T (2005a) Informal logics of risk: contingency and modes of practical reasoning. J Risk Res 8(3):253-272

Horlick-Jones T (2005b) On 'risk work': professional discourse, accountability and everyday action. Health Risk Soc 7(3):293-307

Horlick-Jones T (2008) 'Risk, praxis and everyday life', keynote paper presented to a session on 'The Everyday Management of Risk', International Sociological Association Congress, Barcelona, 5-8 Sept 2008

Horlick-Jones T, Rosenhead J (2002) Investigating risk, organisations and decision support through action research. Risk Manag: Int J 4(4):45-63

Horlick-Jones T, Rosenhead J (2007) The uses of observation: combining problem structuring methods and ethnography. J Oper Res Soc 58:588-601

Horlick-Jones T, Rosenhead J, Georgiou I, Ravetz J, Löfstedt R (2001) Decision support for organisational risk management by problem structuring. Health, Risk Soc 3(2):148-165

Horlick-Jones T, Rosenhead J, Ravetz J, Georgiou, I, Löfstedt R (1998) 'Risk management as therapy: rhetorics, micropolitics and group-based decision support'. Paper presented to the ESRC Risk \& Human Behaviour Programme Conference, SOAS, London, 9-10 Sept 1998

Horlick-Jones T, Sime J (2004) Living on the border: knowledge, risk and transdisciplinarity. Futures 36:441-456

Horlick-Jones T, Walls J, Rowe G, Pidgeon N, Poortinga W, Murdock G, O'Riordan T (2007) The GM debate: risk, politics and public engagement. Routledge, Abingdon

IRGC (2005) Risk governance: towards an integrative approach, white paper No. 1. International Risk Governance Council, Geneva

Jackall R (1988) Moral mazes: The world of corporate managers. Oxford University Press, New York

Klein G, Orasunu J, Calderwood R, Zsambok C (eds) (1993) Decision making in action: models and methods. Ablex, Norwood

Kleindorfer P, Kunreuther H, Schoemaker P (1993) Decision sciences: an integrative perspective. Cambridge University Press, Cambridge 
Klinke A, Renn O (2002) A new approach to risk evaluation and management: risk-based, precautionbased and discourse-based strategies. Risk Anal 22(6):1071-1094

Kovel J (1978) A complete guide to therapy: from psychoanalysis to behaviour modification. Penguin, Harmondsworth

Kunreuther H (1989) The role of actuaries and underwriters in insuring ambiguous risks. Risk Anal 9(3):319-328

Kunreuther H, Meszaros J, Hogarth R, Spanca M (1995) Ambiguity and underwriter decision processes. J Econ Behav Organ 26:337-352

Laing RD (1970) Knots. Tavistock Publications, London

Laing RD, Phillipson H, Lee AR (1966) Interpersonal perception: a theory and method of research. Tavistock Publications, London

Lynch M (1992a) Extending Wittgenstein: the pivotal move from epistemology to the sociology of science. In: Pickering A (ed) Science as practice and culture. University of Chicago Press, Chicago, pp 215-265

Lynch M (1992b) "From the "will to theory" to the discursive collage: a reply to Bloor's "left and right Wittgensteinians". In: Pickering A (ed) Science as practice and culture. University of Chicago Press, Chicago, pp 283-300

Lynch M (1993) Scientific practice and ordinary action: ethnomethodology and social studies of science. Cambridge University Press, Cambridge

Lynch M (1996) Ethnomethodology. In: Kuper A, Kuper J (eds) The Social science encyclopaedia, 2nd edn. Routledge, London, pp 266-267

Mandel M (1996) The High-risk society: peril and promise in the new economy. Times Business Books/ Random House, New York

March JG (1988) Decisions and organizations. Blackwell, Oxford

Molotch H (2012) Against security: How we go wrong at airports, subways and other sites of ambiguous danger. Princeton University Press, Princeton

Molotch H, McClain N (2008) Things at work: informal social-material mechanisms for getting the job done. J Consum Culture 8(1):35-67

NAO (2000) Supporting innovation: managing risk in government departments, National Audit Office report by the Comptroller and Auditor General, HC 864, Session 1999-2000. The Stationery Office, London

NAO (2004) Managing risks to Improve public service, National Audit Office report by the Comptroller and Auditor General, HC 1078-1, Session 2003-2004. The Stationery Office, London

National Research Council (1996) Understanding risk: informing decisions in a democratic society. National Academy Press, Washington, DC

National Research Council (2008) Public participation in environmental assessment and decision making. National Academies Press, Washington, DC

Penn P (1982) Circular questioning. Fam Process 21:267-280

Peräkylä A, Antaki C, Vehviläinen S, Leudar I (eds) (2008) Conversation analysis and psychotherapy. Cambridge University Press, Cambridge

Phillips A (1988) Winnicott. Fontana, London

Phillips L, Phillips M (1993) Facilitated work groups: theory and practice. J Oper Res Soc 44(6):533-549

Power M (2004) The Risk management of everything: rethinking the politics of uncertainty. Demos, London

Power M, Scheytt T, Soin K, Sahlin K (2009) Reputational risk as a logic of organizing in late modernity. Organ Stud 30(2-3):301-324

Prior L (2001) Rationing through risk assessment in clinical genetics: all categories have wheels. Sociol Health Illn 23(1):570-593

Ravetz J (1971) Scientific knowledge and its social problems. Oxford University Press, Oxford

Renn O (2008) Risk governance: coping with uncertainty in a complex world. Earthscan, London

Renn O, Webler T, Wiedemann P (eds) (1995) Fairness and competence in citizen participation: evaluating models for environmental discourse. Kluwer, Dordrecht

Rittel HWJ, Webber MM (1973) Dilemmas in a general theory of planning. Policy Sci 4:155-169

Rosenhead J (2005) Controversy on the streets: stakeholder workshops on a choice of carnival route. In: Friend J, Hickling A (eds) Planning under pressure the strategic choice approach, 3rd edn. Elsevier Butterworth-Heinemann, Oxford, pp 298-302

Rosenhead J, Horlick-Jones T (1995) Problem structuring and risk analysis, papers on risk in organisational settings. ESRC Risk \& Human Behaviour Programme, New York 
Rosenhead J, Mingers J (eds) (2001) Rational analysis for a problematic world revisited: problem structuring methods for complexity, uncertainty and conflict. Wiley, Chichester

Roy D (1960) 'Banana time': job satisfaction and informal interaction. Hum Organ 18(2):156-168

RSSB (2006) Decision-taking framework: a systematic approach to taking railway decisions that have an impact on safety, discussion paper. Railway Safety and Standards Board, London

Schein E (1987) Process consultation volume II: lessons for manager and consultants. Addison-Wesley, Reading

Schein E (1988) Process consultation volume I: its role in organization development, 2nd edn. AddisonWesley, Reading

Schön D, Rein M (1994) Frame reflection: toward the resolution of intractable Policy Controversies. Basic Books, New York

Schön D (1983) The reflective practitioner: how professionals think in action. Basic Books, New York

Sharpe A (2004) Safety decision making for the railway. In: Redmill F, Anderson T (eds) Practical elements of safety: proceedings of the twelfth safety-critical systems symposium. Springer-Verlag, London

Storr A (1979) The art of psychotherapy. Secker \& Warburg and Heinemann Medical Books, London

Tait J (2001) More Faust than Frankenstein: the European debate about the Precautionary principle and risk regulation for genetically-modified crops. J Risk Res 4(2):175-189

Tett G (2009) Fool's gold: How unrestrained greed corrupted a dream, shattered global markets and unleashed a catastrophe. Little, Brown, London

UKOOA (1999) Industry guidelines on a framework for risk-related decision support. UK Offshore Operators Association, London

Weakland J, Fisch R, Watzlawick P, Bodin A (1974) Brief therapy: focused problem resolution. Fam Process 13:141-168

Webler T (1995) Right discourse in citizen participation: an evaluative yardstick. In: Renn O, Webler T, Wiedemann P (eds) Fairness and competence in citizen participation: evaluating models for environmental discourse. Kluwer, Dordrecht, pp 35-86

Winnicott D (1971) Playing and reality. Tavistock Publications, London

Wittgenstein L (1958) Philosophical investigations, 2nd edn. Blackwell, Oxford

Wynne B (1992) Uncertainty and environmental learning: reconceiving science and policy in the preventive paradigm. Global environmental change 2:111-127 